Research Article

\title{
Cefpodoxime Proxetil: A New Stability Indicating RP-HPLC Method
}

\author{
Ceema Mathew, ${ }^{1,2}$ M. Ajitha, ${ }^{2}$ and P. R. Sathesh Babu ${ }^{1}$ \\ ${ }^{1}$ Gokaraju Rangaraju College of Pharmacy, Osmania University, Bachupally, Hyderabad 500 090, India \\ ${ }^{2}$ Jawaharlal Nehru Technological University, Hyderabad 500 085, India \\ Correspondence should be addressed to Ceema Mathew; nirujose@gmail.com
}

Received 24 April 2013; Accepted 29 May 2013

Academic Editors: J. A. P. Coelho, B. Fernandez De Simon, and M. Hassan

Copyright (c) 2013 Ceema Mathew et al. This is an open access article distributed under the Creative Commons Attribution License, which permits unrestricted use, distribution, and reproduction in any medium, provided the original work is properly cited.

\begin{abstract}
The present work describes the development of a sensitive and economic stability indicating high performance liquid chromatographic (HPLC) method for the determination of cefpodoxime proxetil (CP) as bulk drug and as pharmaceutical formulation. Both R and S isomers of the drug were separated using Phenomenex $(250 \times 4.6 \mathrm{~mm}, 5 \mu \mathrm{m}$ particle size $)$ ODS column with a flow rate of $1 \mathrm{~mL} \mathrm{~min}^{-1}$ and an SPD $20 \mathrm{~A} \mathrm{UV}$ detector to monitor the eluate at $252 \mathrm{~nm}$. The isocratic method used a mobile phase consisting of methanol and phosphate buffer of $\mathrm{pH} 4.0$ in the ratio $65: 35$. The linear regression analysis data for the calibration plots showed good linear relationship with $R^{2}=0.9999$ in the working concentration range of $5-100 \mu \mathrm{g} \mathrm{mL}^{-1}$. The LOD and LOQ were 53 and $160 \mathrm{ng} \mathrm{mL}^{-1}$, respectively. CP was subjected to stress degradation using acid, alkali, hydrogen peroxide, dry heat, wet heat, and UV light. The standard drug peaks were well resolved from the degradation products' peaks with significantly different retention time (Rt), and the resolution factor for the R and S isomers of CP was found to be greater than 2.
\end{abstract}

\section{Introduction}

Stability indicating methods are the quantitative analytical methods that are based on the characteristic structural, chemical, or biological properties of each active ingredient of a drug product and that will distinguish each active ingredient from its degradation products so that the active ingredient content can be accurately measured [1]. The International Conference on Harmonization (ICH) guideline entitled "Stability Testing of New Drug Substances and Products" requires that stress testing be carried out to elucidate the inherent stability characteristics of the active substance [2]. Acidic, alkaline, oxidative, and photolytic stabilities are required. An ideal stability indicating method is the one that quantifies the standard drug alone and also resolves it from its degradation products [3].

Stability indicating method is an analytical procedure that is capable of discriminating between the major active pharmaceutical ingredient (API) and any degradation (decomposition) product(s) formed under defined storage conditions during the stability evaluation period [4]. Cefpodoxime proxetil $(\mathrm{CP})$ is a prodrug that is deesterified in vivo to its active metabolite, cefpodoxime, to exhibit antibiotic activity [5-9]. The structure of CP is given in Figure 1. It is active against most Gram positive and Gram negative organisms. It is commonly used in the treatment of a variety of infections of skin, respiratory tract, urinary tract, and systemic infections and also to treat acute otitis media, pharyngitis, and sinusitis. $\mathrm{CP}$ is supplied as a racemic mixture of two enantiomers $\mathrm{R}$ and $S$ in a ratio of about $1: 1$ [7]. There are some reported methods for the quantification of cefpodoxime proxetil alone and in combination with potassium clavulanate [10-14], and there are a few stability indicating assay methods and methods for related substances [15-19].

In many of the HPLC methods, acetonitrile is used as the organic phase. It is a toxic chemical as it can cause environmental pollution and health hazards to human beings and animals [20]. As per the available literature, the mobile phase for $\mathrm{CP}$ is either acetonitrile and buffer or acetonitrile, methanol, and buffer in different ratios. In an attempt to practice green chemistry, in the present investigation, it is substituted with less toxic and less expensive methanol for 


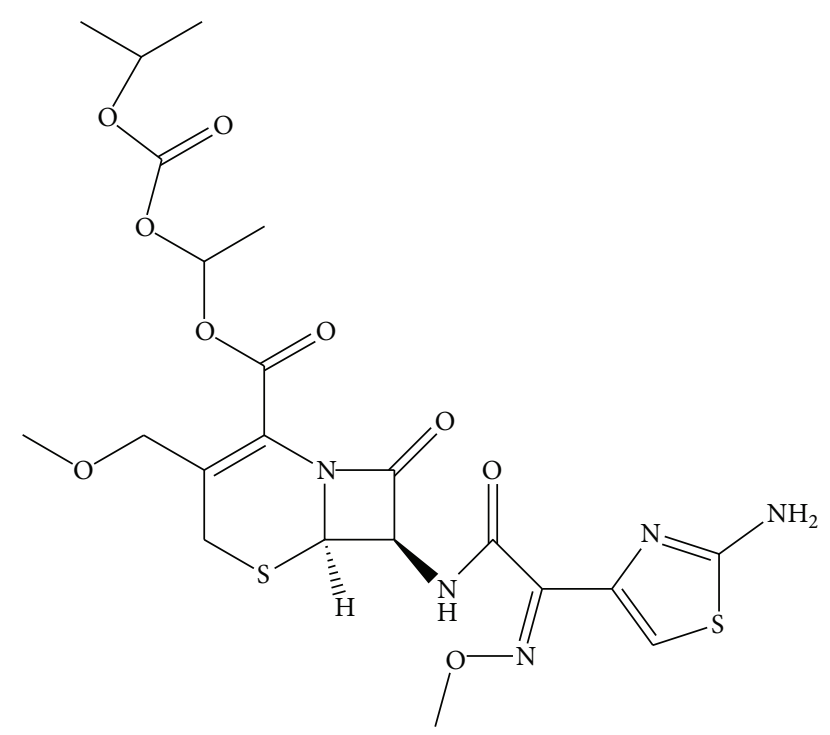

Figure 1: Structure of Cefpodoxime proxetil (CP).

the development of a cost effective and safer analytical methodology that can quantify CP in pharmaceutical dosage forms and resolve the pure drug from its degradation products.

\section{Experimental}

2.1. Materials and Reagents. Cefpodoxime proxetil API (with a purity of $99.30 \%$ which contains both $\mathrm{R}$ and $\mathrm{S}$ isomers) was available as a gift sample from See Gee Pharmaceuticals Pvt. Ltd., Puducherry. Methanol, disodium hydrogen phosphate, and potassium dihydrogen phosphate were purchased from S.D Fine Chemicals (Mumbai, India) and were of HPLC grade. Hydrochloric acid, sodium hydroxide pellets, hydrogen peroxide, and orthophosphoric acid were purchased from S.D Fine Chemicals (Mumbai, India) and were of A.R grade. Purified water was prepared in-house by distillation of water in triplicate followed by filtration through filter paper of $0.45 \mu \mathrm{m}$ pore size and $47 \mathrm{~mm}$ diameter.

2.2. HPLC Instrumentation. The HPLC system consists of a Shimadzu LC $20 \mathrm{AD}$ binary pump and SPD $20 \mathrm{~A} \mathrm{UV}$ detector. The column consists of Phenomenex $(250 \mathrm{~mm}$ length, $4.6 \mathrm{~mm}$ internal diameter, and $5 \mu \mathrm{m}$ particle size) ODS. LC Solution software was used for data acquisition. Sample injection was done by Rheodyne manual injector.

2.3. Chromatographic Conditions and Mobile Phase Preparation. Chromatographic separation was achieved using Phenomenex ODS column. The LC system was operated isocratically using a mobile phase consisting of a mixture of methanol and phosphate buffer of $\mathrm{pH} 4.0$ (prepared with $5.04 \mathrm{~g}$ of disodium hydrogen phosphate and $3.01 \mathrm{~g}$ potassium dihydrogen phosphate dissolved in $1000 \mathrm{~mL}$ of triple distilled water and the $\mathrm{pH}$ was adjusted to 4.0 using orthophosphoric acid) in the ratio of $65: 35$ as the mobile phase at a flow rate of $1.0 \mathrm{~mL} / \mathrm{min}$ at room temperature. The injection volume was $20 \mu \mathrm{L}$ for both standard and sample. The UV detector was set at $252 \mathrm{~nm}$, and the peak areas were integrated automatically using LC Solution software. Peak identity was confirmed by retention time comparison.

\subsection{Procedures}

2.4.1. Preparation of Cefpodoxime Proxetil Standard. The stock solution of CP was prepared by weighing $10 \mathrm{mg}$ of the reference substance and transferring it to a $10 \mathrm{~mL}$ volumetric flask, diluting to $10 \mathrm{~mL}$ with methanol $(1000 \mu \mathrm{g} / \mathrm{mL})$. The working standard solution $(100 \mu \mathrm{g} / \mathrm{mL})$ was obtained by dilution of the stock solution using mobile phase.

2.4.2. Preparation of Sample Solution. Two brands of cefpodoxime tablets (Cefoact-100 mg, Cepodem-100 mg) were purchased from a local pharmacy. Twenty tablets of each brand were accurately weighed and crushed to fine powder separately. A quantity of powder equivalent to $25 \mathrm{mg}$ of $\mathrm{CP}$ was transferred to a $25 \mathrm{~mL}$ volumetric flask and added $10 \mathrm{~mL}$ of methanol, kept in an ultrasonic bath for $10 \mathrm{~min}$ and made up to the volume with methanol and filtered.

2.5. Validation Study. The developed method was validated as per ICH guidelines using CP with respect to the following parameters: accuracy, precision, LOD, LOQ, specificity, robustness, stability, and system suitability.

2.5.1. Linearity. For testing linearity, seven calibration standards were prepared in the range of 5 to $100 \mu \mathrm{g} / \mathrm{mL}(5,10,20$, $40,60,80$, and $100 \mu \mathrm{g} / \mathrm{mL})$. Standard curve was obtained by plotting peak area against concentration, and the evaluation of linearity was done by linear regression analysis using least square method.

2.5.2. Limit of Detection and Limit of Quantitation. Normally, limit of detection (LOD) and limit of quantitation (LOQ) are estimated at a signal to noise ratio of $3: 1$ and $10: 1$, respectively. LOD and LOQ were calculated using (1) and (2), respectively. The theoretical values were confirmed practically by injecting dilute solutions of known concentration.

Consider

$$
\begin{aligned}
& \mathrm{LOD}=\mathrm{SD} \times \frac{3.3}{S}, \\
& \mathrm{LOQ}=\mathrm{SD} \times \frac{10}{S},
\end{aligned}
$$

where SD is the standard deviation of the area of lowest concentration, and $S$ is the slope of the calibration graph.

2.5.3. Specificity. Specificity is the ability of a method to measure analytical response in presence of its potential impurities. Specificity of the method was carried out by the deliberate degradation of the drug by oxidation, heat, hydrolysis (acidic, alkaline, neutral), and photolysis, followed by its analysis using the developed method. 


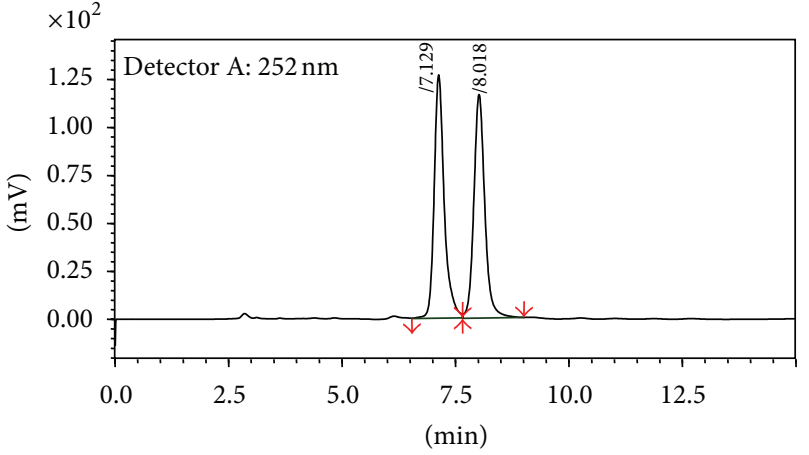

(a)

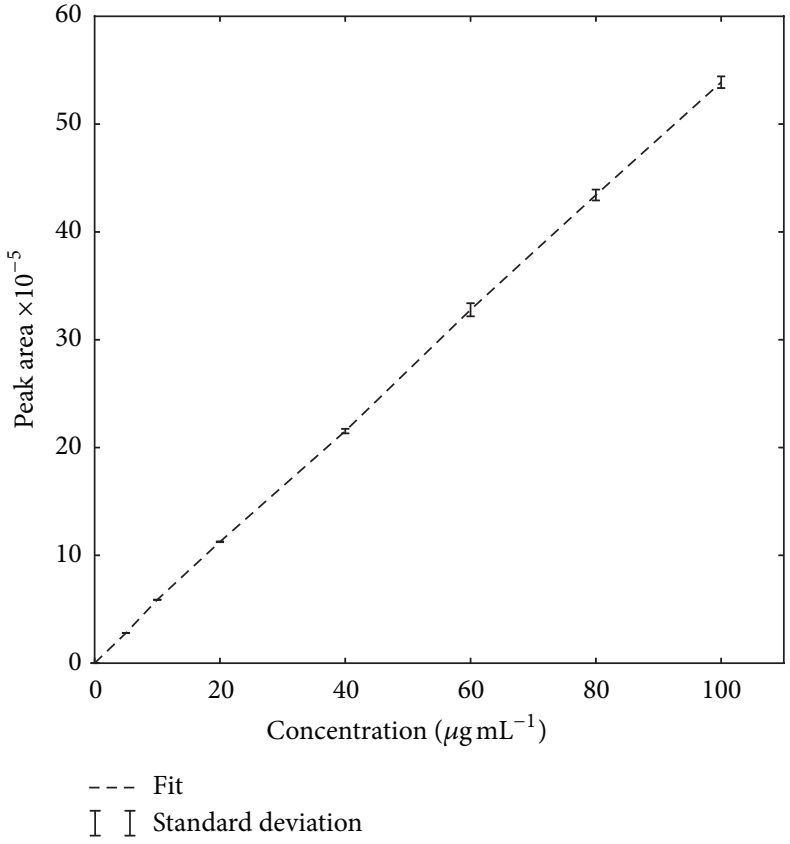

(b)

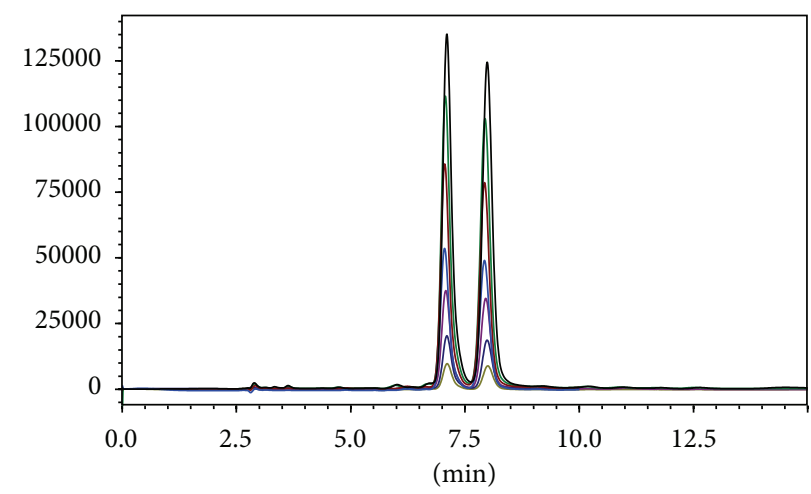

(c)

Figure 2: (a) Chromatogram of CP standard $100 \mu \mathrm{gL}^{-1}$. (b) Linearity graph of CP $\left(5,10,20,40,60,80\right.$, and $\left.100 \mu \mathrm{g} \mathrm{mL} \mathrm{m}^{-1}\right)$. (c) Overlay chromatogram of CP $\left(5,10,20,40,60,80\right.$, and $\left.100 \mu \mathrm{g} \mathrm{mL}^{-1}\right)$.

2.5.4. Robustness. Experimental conditions were deliberately altered, and resolution of CP from its degradation products was noticed, in order to determine the robustness. From the different experimental conditions such as flow rate $(1.0 \mathrm{~mL} / \mathrm{min})$, lambda $\max (252 \mathrm{~nm})$, and percentage of methanol (65), each selected factor was changed at three levels $(-1,0$, and +1$)$. One factor was changed at a time to study the impact of the change in the experimental conditions on the assay results. Difference in the peak area and the retention time were noted at each change in the analytical parameters.

2.5.5. Stability of Sample Solution. Sample solution was prepared and analysed by the HPLC instrument using fresh mobile phase at different time intervals $(0 \mathrm{~h}, 8 \mathrm{~h}$, and $24 \mathrm{~h})$.
TABLE 1: Stability of sample solution.

\begin{tabular}{|c|c|c|}
\hline $\begin{array}{l}\text { Concentration of std. } \\
(\mu \mathrm{g} / \mathrm{mL})\end{array}$ & $\begin{array}{c}\text { Postpreparation } \\
\text { time in } \mathrm{h}\end{array}$ & Peak area \\
\hline 100 & 0 & 5329310 \\
\hline 100 & 8 & 5239298 \\
\hline 100 & 24 & 5361394 \\
\hline$\% \mathrm{RSD}$ & \multicolumn{2}{|c|}{1.19} \\
\hline
\end{tabular}

2.5.6. Accuracy. Accuracy of the developed method was assessed in triplicate at three concentrations (40, 60, and $80 \mu \mathrm{g} / \mathrm{mL}$ ). The percentage recovery was calculated from the linear regression equation obtained in the linearity studies. 


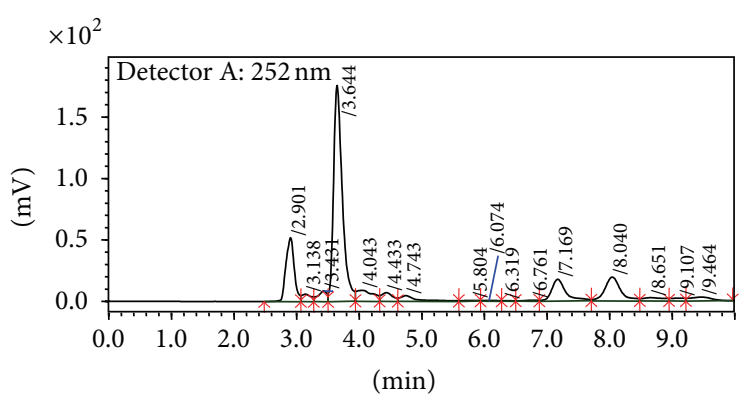

(a)

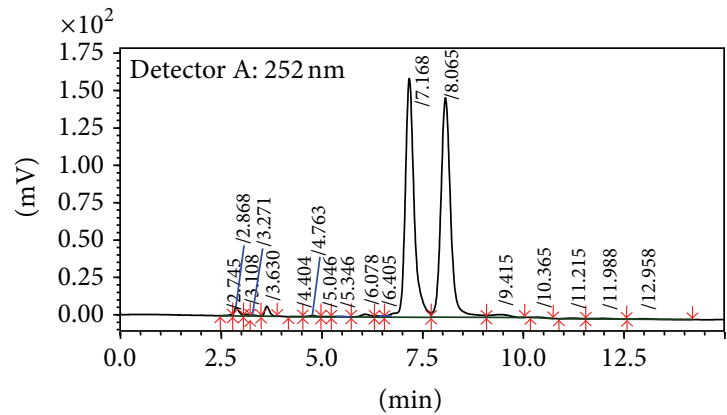

(c)

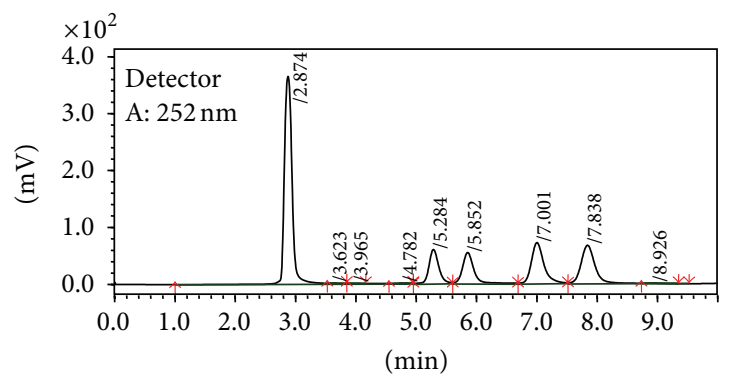

(e)

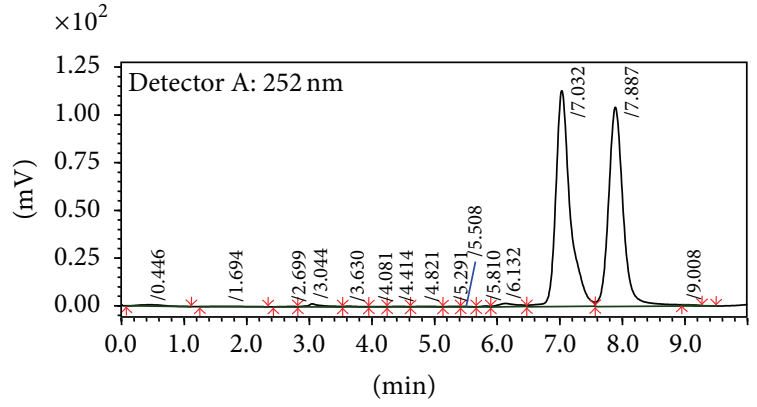

(b)

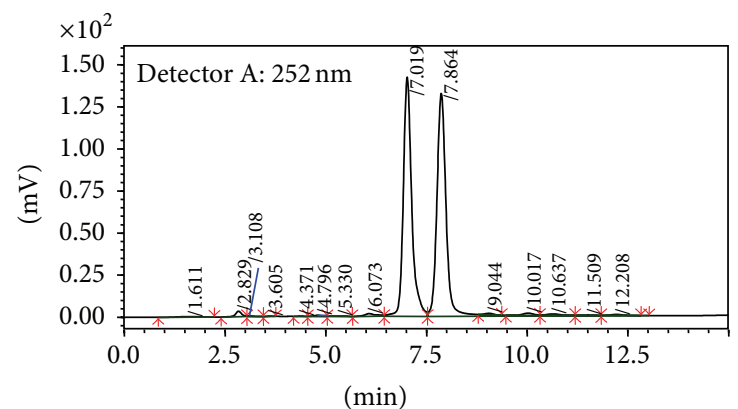

(d)

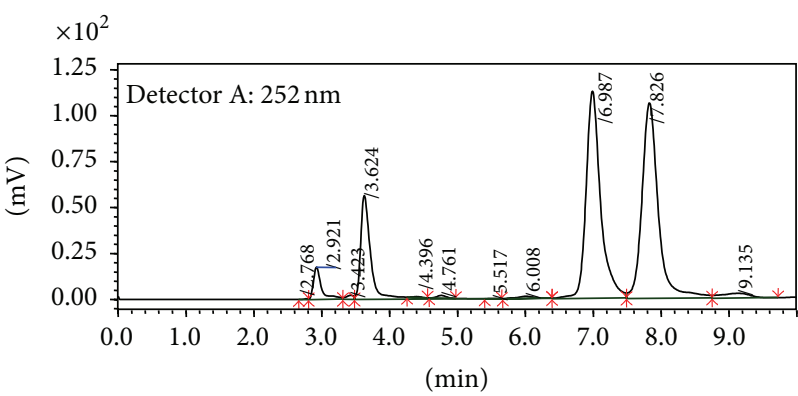

(f)

Figure 3: (a) Chromatogram for alkaline $(0.1 \mathrm{~N} \mathrm{NaOH})$ degradation. (b) Chromatogram for dry heat degradation. (c) Chromatogram for hydrolytic degradation. (d) Chromatogram for photolytic degradation. (e) Chromatogram for oxidative degradation. (f) Chromatogram for acidic $(1 \mathrm{~N} \mathrm{HCl})$ degradation.

TABLE 2: Intra- and interday precision.

\begin{tabular}{|c|c|c|c|c|c|c|}
\hline \multirow{2}{*}{ Con. $\left(\mu \mathrm{g} \mathrm{mL}^{-1}\right)$} & \multicolumn{3}{|c|}{ Intraday precision $^{\mathrm{a}}$} & \multicolumn{3}{|c|}{ Interday precision $^{\mathrm{b}}$} \\
\hline & Mean con. & SD & $\%$ RSD & Mean con. & $\mathrm{SD}$ & $\%$ RSD \\
\hline 40.0 & 40.60 & 0.072 & 0.178 & 40.55 & 0.405 & 1.000 \\
\hline 60.0 & 60.43 & 0.300 & 0.496 & 60.73 & 0.130 & 0.215 \\
\hline 80.0 & 80.33 & 0.154 & 0.192 & 80.37 & 0.346 & 0.431 \\
\hline
\end{tabular}

Mean concentration of six trials. ${ }^{\mathrm{b}}$ Mean concentration of nine trials.

TABLE 3: Recovery studies.

\begin{tabular}{lccc}
\hline \multirow{2}{*}{ Excess drug added to analyte (\%) } & \multicolumn{2}{c}{ Drug content in $\mu \mathrm{g} \mathrm{mL}^{-1}$} & \multicolumn{2}{c}{ Recovery (\%) } \\
\hline 0 & Theoretical & Practical $^{\mathrm{a}}$ & 0.687 \\
16 & 20 & 20.49 & 102.46 \\
20 & 36 & 36.08 & 100.236 \\
24 & 40 & 40.90 & 102.253 \\
\hline
\end{tabular}

Mean concentration of six trials. 


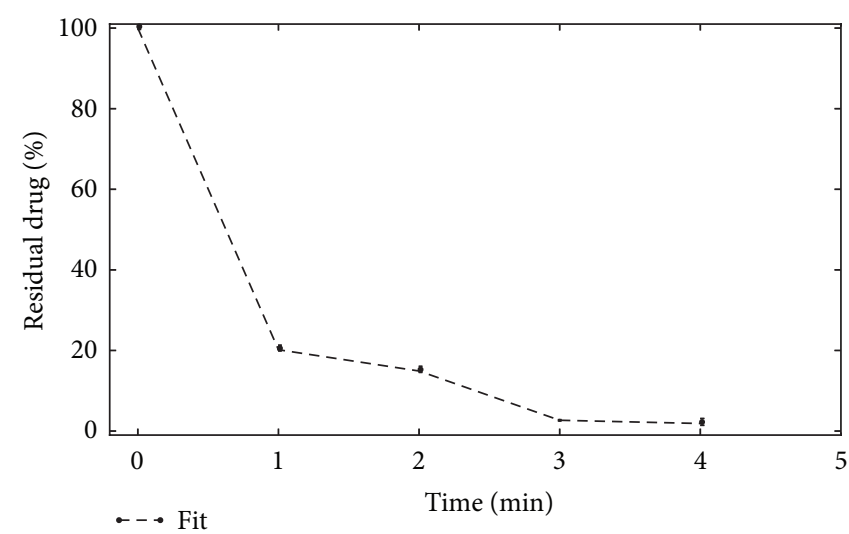

I I Standard deviation

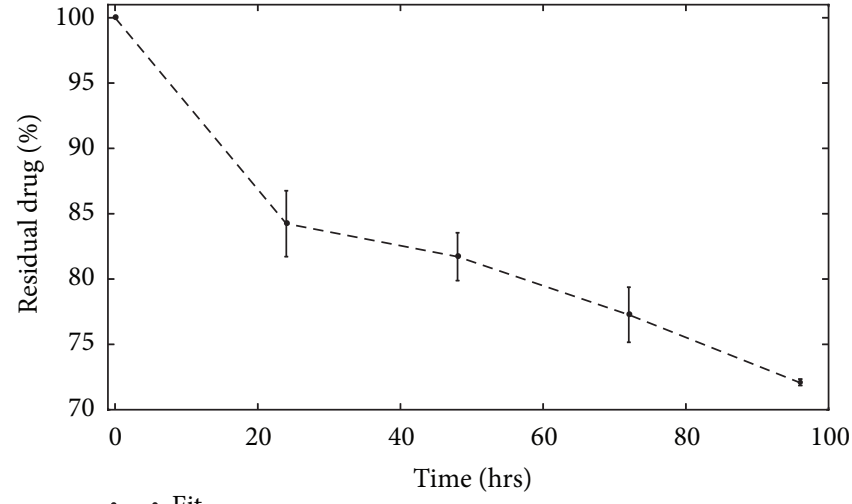

$\rightarrow$ Fit

I I Standard deviation

(a)

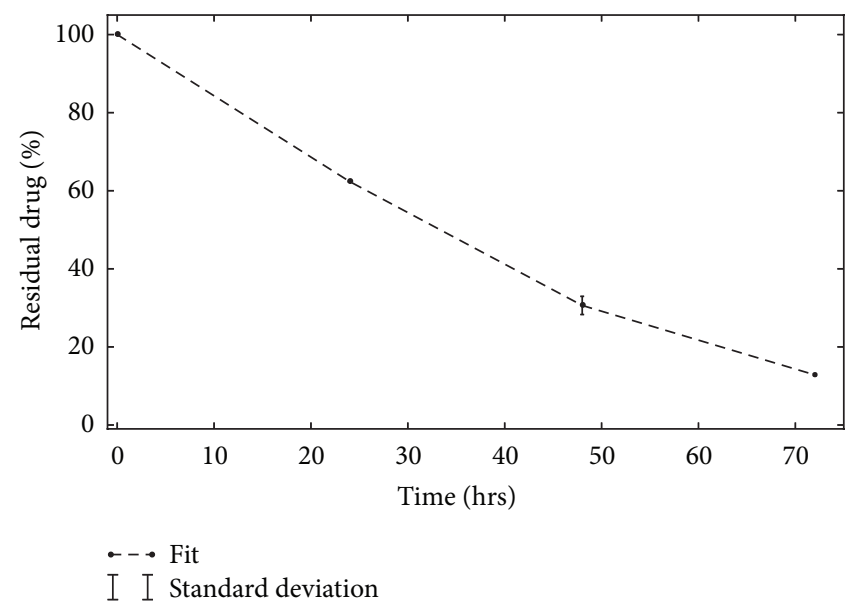

(c)

FIGURE 4: Kinetics of degradation plotted as residual drug (\%) \pm SD versus time for (a) acidic degradation, (b) alkaline degradation, and (c) oxidative degradation.

TABLE 4: Analysis of the marketed formulation.

\begin{tabular}{lcccc}
\hline Formulation & Labelled amount & Amount found \pm SD $^{\text {a }}$ & \% RSD & \% Assay \\
\hline Tablet Cefoact & 100 mg per tablet & $101.04 \pm 0.84$ & 0.415 & 101.04 \\
Tablet Cepodem & 100 mg per tablet & $101.78 \pm 0.06$ & 0.027 & 101.77 \\
\hline
\end{tabular}

Mean concentration of three trials.

2.5.7. Precision. The precision of the analytical method was evaluated by the determination of the repeatability of the method (intraday precision) and intermediate precision (interday precision) of the sample solutions. Repeatability was calculated by assaying six samples prepared on the same day. Intermediate precision was calculated by assaying 3 days. The relative standard deviation of the area of peaks was calculated.

\section{Results and Discussion}

3.1. Optimization of Chromatographic Condition. The chromatographic conditions were optimized with a view to obtain symmetrical peaks with good resolution between the R and S optical isomers of cefpodoxime proxetil. At the same time, these peaks should be well separated from the degradation peaks so that they can be quantified even in the presence of degradants. Separation was achieved using a mobile phase consisting of methanol and phosphate buffer of $\mathrm{pH} 4.0(\mathrm{pH}$ was adjusted to 4.0 with o-phosphoric acid) in the ratio of $65: 35$ by an isocratic profile, pumped at a flow rate of

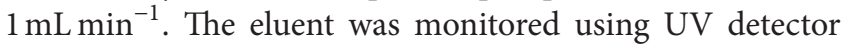
at a wavelength of $252 \mathrm{~nm}$. The column was maintained at ambient temperature with an injection volume of $20 \mu \mathrm{L}$.

3.2. Limit of Detection and Limit of Quantitation. Concentrations of LOD and LOQ were found to be 53 and $160 \mathrm{ng} / \mathrm{mL}$, respectively. 
TABLE 5: Robustness evaluation. ${ }^{\mathrm{a}}$

\begin{tabular}{|c|c|c|c|c|}
\hline \multicolumn{5}{|c|}{ Retention time (Rt) for both isomers of CP ( $\mathrm{min})$} \\
\hline \multicolumn{5}{|c|}{ (A) Flow rate $\left(\mathrm{mL} \mathrm{min}^{-1}\right)$} \\
\hline 0.95 & -1 & 7.212 & 8.122 & 5280908 \\
\hline 1 & 0 & 7.066 & 7.927 & 5239656 \\
\hline 1.05 & +1 & 6.99 & 7.836 & 5272832 \\
\hline & $=3)$ & $7.089 \pm 0.113$ & $7.962 \pm 0.146$ & $5264465 \pm 21861$ \\
\hline \multicolumn{5}{|c|}{ (B) Percentage of methanol in mobile phase } \\
\hline 64 & -1 & 7.133 & 8.01 & 5339448 \\
\hline 65 & 0 & 7.066 & 7.927 & 5239656 \\
\hline 66 & +1 & 6.911 & 7.82 & 5311649 \\
\hline & $=3)$ & $7.037 \pm 0.114$ & $7.934 \pm 0.099$ & $5296917.67 \pm 51501$ \\
\hline \multicolumn{5}{|c|}{ (C) Wavelength of measurement } \\
\hline 251 & -1 & 7.068 & 7.932 & 5256020 \\
\hline 252 & 0 & 7.066 & 7.927 & 5239656 \\
\hline 253 & +1 & 7.095 & 7.912 & 5369302 \\
\hline & $=3)$ & $7.0763 \pm 0.016$ & $7.924 \pm 0.010$ & $5288326 \pm 70603$ \\
\hline
\end{tabular}

Mean values of six trials.

TABLE 6: Residual drug (\%) after acidic degradation $(n=3)$.

\begin{tabular}{lc}
\hline Time in h & Residual drug $(\%) \pm$ SD \\
\hline 0 & $100 \pm 0$ \\
24 & $84.21 \pm 2.52$ \\
48 & $82.49 \pm 1.83$ \\
72 & $77.25 \pm 2.11$ \\
96 & $72.07 \pm 0.20$ \\
\hline
\end{tabular}

TABLE 7: Residual drug (\%) after alkaline degradation $(n=3)$.

\begin{tabular}{lc}
\hline Time in min & Residual drug (\%) \pm SD \\
\hline 0 & $100 \pm 0$ \\
1 & $20.17 \pm 0.29$ \\
2 & $14.90 \pm 0.34$ \\
3 & $2.67 \pm 0.15$ \\
4 & $1.87 \pm 0.052$ \\
\hline
\end{tabular}

3.3. Linearity. The linearity graph is given in Figure 2(b), and the chromatograms of the different concentrations are shown as an overlay chromatogram in Figure 2(c).

The regression equation for the graph is $y=53828 x+$ 24883 , and the correlation coefficient $R^{2}$ is 0.9999 showing excellent correlation between the area and the concentration.

3.4. Stability of Sample Solution. The drug was found to be stable in the mobile phase. This was proved by injecting the standard solution at 0,8 , and $24 \mathrm{~h}$ after preparation which showed the absence of any extra peaks due to degradation, and there was not much change in the drug peak area (\% RSD = 1.19) (Table 1).

3.5. Precision. The percentage relative standard deviation (\% $\mathrm{RSD}$ ) of the area of $\mathrm{CP}$ during intraday study was found to be
TABLE 8: Residual drug (\%) after oxidative degradation $(n=3)$.

\begin{tabular}{lc}
\hline Time in $h$ & Residual drug $(\%) \pm$ SD \\
\hline 0 & $100 \pm 0$ \\
24 & $62.34 \pm 0.12$ \\
48 & $30.62 \pm 2.33$ \\
72 & $12.84 \pm 0.22$ \\
\hline
\end{tabular}

less than 0.4 and for interday study was found to be less than 1.1, which indicated a good precision of the method (Table 2).

3.6. Accuracy. The quantitative recovery of $\mathrm{CP}$ achieved ranged from 100.24 to $102.25 \%$ with a low \% RSD value. The results of the recovery experiments done at 3 concentration levels and the \% RSD values are given in Table 3.

3.7. Analysis of the Marketed Formulation. The validated method was applied for the assay of CP in 2 brands of cefpodoxime tablets (Cefoact-100 mg, Cepodem-100 mg) (Table 4). Due to the absence of extra peaks in the chromatogram, it can be concluded that there was no interference from the excipients in the formulations.

3.8. Robustness. The results in the robustness study, as shown in Table 5, indicated that the results are not much affected by the small variations in the selected parameters.

3.9. Specificity. In order to check the specificity of the proposed method, degradation studies were carried out by using acidic, basic, photolytic, oxidative, and thermal conditions. Cefpodoxime proxetil active pharmaceutical ingredient (API) powder was stressed under various conditions to conduct forced degradation studies. Intentional degradation was performed by subjecting it to various stress conditions of 
TABLE 9: Degradation rate constant and half-life.

\begin{tabular}{lccc}
\hline Sl. no. & Stress condition & Rate constant & Half-life \\
\hline$(1)$ & Alkaline $(0.1 \mathrm{~N})$ & $0.021 \mathrm{sec}^{-1}$ & $33.10 \mathrm{sec}$ \\
$(2)$ & Oxidative $\left(3 \% \mathrm{v} / \mathrm{v} \mathrm{H} \mathrm{H}_{2}\right)$ & $0.023 \mathrm{~h}^{-1}$ & $29.96 \mathrm{~h}$ \\
$(3)$ & Acidic $(1 \mathrm{~N})$ & $0.0029 \mathrm{~h}^{-1}$ & $302.18 \mathrm{~h}$ \\
\hline
\end{tabular}

acidic $(1 \mathrm{~N} \mathrm{HCl})$, basic $(0.1 \mathrm{~N} \mathrm{NaOH})$, neutral (water), oxidative $\left(3 \% \mathrm{H}_{2} \mathrm{O}_{2}\right)$, thermal (heated at $\left.105^{\circ} \mathrm{C}\right)$, and photolytic degradation to evaluate the ability of the proposed method to separate CP from its degradation products. Chromatogram of $\mathrm{CP}$, along with the degradation products under various stress conditions, is shown in Figures 3(a) to 3(f).

The degradation kinetics of CP was performed by extending the stress degradation to various time intervals for acidic, alkaline, and oxidative stress, the data of which is given in Tables 6, 7, and 8 as the residual drug (\%) in comparison with the zero time sample concentration, and the corresponding graphs are given in Figures 4(a) to 4(c). The graphs clearly indicate that the drug is highly susceptible to alkaline degradation (Figure 4(b)) and it is almost completely degraded within $5 \mathrm{~min}$, after which there is no sample peak. It is further confirmed by the short half-life of $33.10 \mathrm{sec}$ for alkaline degradation. By plotting the logarithm of the drug concentration versus time, a straight line is obtained which indicates that the degradation reactions are of first order. The degradation rate constant $(K)$ and half-life are calculated and are given in Table 9.

\section{Conclusion}

An economic stability indicating HPLC method has been developed and validated for the determination of CP in API and different pharmaceutical formulations. The method is accurate, precise, and specific and also has the ability to analyse the drug in presence of its degradation products, and it can be employed as a stability indicating assay. The drug peak was well separated from degradation products' peaks. The most interesting fact is that the method could separate the $\mathrm{R}$ and $\mathrm{S}$ isomers without the use of a chiral column or a chiral selector. On comparing the stability of the drug under different stresses, it had undergone faster degradation in alkaline condition, as the drug was almost completely degraded within $4 \mathrm{~min}$ and then in oxidative condition. In acidic media, the drug was comparatively stable.

\section{Conflict of Interests}

The authors declare no conflict of interests.

\section{Acknowledgments}

The authors wish to thank the principal, Professor C. V. S. Subrahmanyam, and the management of Gokaraju Rangaraju College of Pharmacy, Bachupally, Hyderabad, for wholeheartedly supporting this work.

\section{References}

[1] Guidelines for Submitting Documentation for the Stability of Human Drugs and Biologics, Food and Drug Administration, Rockvillae, Md, USA, 1987.

[2] "Stability testing of new drug substances and products Q1A," in Proceedings of the International Conference on Harmonization, Geneva, Switzerland, 1993.

[3] M. Bakshi and S. Singh, "Development of validated stabilityindicating assay methods-critical review," Journal of Pharmaceutical and Biomedical Analysis, vol. 28, no. 6, pp. 1011-1040, 2002.

[4] J. T. Carstensen and C. T. Rhodes, "Development and validation of HPLC stability indicating assays," in Drug StabilityPrinciples and Practices, p. 331, Marcel Dekker, New York, NY, USA, 3rd edition, 2005.

[5] M. T. Borin, "A review of the pharmacokinetics of cefpodoxime proxetil”, Drugs, vol. 42, supplement 3, pp. 13-21, 1991.

[6] E. Bergogne-Berezin, "Cefpodoxime in upper respiratory tract infections," Drugs, vol. 42, no. 3, pp. 25-33, 1991.

[7] A. M. Geddes, "Cefpodoxime proxetil in the treatment of lower respiratory tract infections," Drugs, vol. 42, supplement 3, pp. 34-40, 1991.

[8] V. K. Kakumanu, V. Arora, and A. K. Bansal, "Investigation on physicochemical and biological differences of cefpodoxime proxetil enantiomers," European Journal of Pharmaceutics and Biopharmaceutics, vol. 64, no. 2, pp. 255-259, 2006.

[9] E. C. Chocas, C. M. Paap, and P. J. Godley, "Cefpodoxime proxetil: a new, broad-spectrum, oral cephalosporin," Annals of Pharmacotherapy, vol. 27, no. 11, pp. 1369-1377, 1993.

[10] F. Camus, A. Deslandes, L. Harcouet, and R. Farinotti, "Highperformance liquid chromatographic method for the determination of cefpodoxime levels in plasma and sinus mucosa," Journal of Chromatography B, vol. 656, no. 2, pp. 383-388, 1994.

[11] V. K. Kakumanu, V. K. Arora, and A. K. Bansal, "Development and validation of isomer specific RP-HPLC method for quantification of cefpodoxime proxetil," Journal of Chromatography $B$, vol. 835, no. 1-2, pp. 16-20, 2006.

[12] M. J. Lovdahl, K. E. Reher, H. Q. Russlie, and D. M. Canafax, "Determination of cefpodoxime levels in chinchilla middle ear fluid and plasma by high-performance liquid chromatography," Journal of Chromatography B, vol. 653, no. 2, pp. 227-232, 1994.

[13] S. Malathi, R. N. Dubey, and R. Venkatnarayanan, "Simultaneous RP-HPLC estimation of cefpodoxime proxetil and clavulanic acid in tablets," Indian Journal of Pharmaceutical Sciences, vol. 71, no. 1, pp. 102-105, 2009.

[14] F. Molina, F. Jehl, C. Gallion, F. Penner, and H. Monteil, "Determination of the third generation oral cephalosporin cefpodoxime in biological fluids by high-speed high-performance liquid chromatography," Journal of Chromatography B, vol. 563, no. 1, pp. 205-210, 1991. 
[15] G. Patel and S. Rajput, "Stress degradation studies on cefpodoxime proxetil and development of a validated stabilityindicating HPLC method," Acta Chromatographica, vol. 23, no. 2, pp. 215-234, 2011.

[16] N. Fukutsu, T. Kawasaki, K. Saito, and H. Nakazawa, "Application of high-performance liquid chromatography hyphenated techniques for identification of degradation products of cefpodoxime proxetil," Journal of Chromatography A, vol. 1129, no. 2, pp. 153-159, 2006.

[17] K. Stoeckel, W. Hofheinz, J. P. Laneury, P. Duchene, S. Shedlofsky, and R. A. Blouin, "Stability of cephalosporin prodrug esters in human intestinal juice: implications for oral bioavailability," Antimicrobial Agents and Chemotherapy, vol. 42, no. 10, pp. 2602-2606, 1998.

[18] M.-J. Wang, W.-B. Zou, J. Xue, and C.-Q. Hu, "Comparison of three RP-HPLC methods for analysis of cefpodoxime proxetil and related substances," Chromatographia, vol. 65, no. 1-2, pp. 69-75, 2007.

[19] P. Jain, A. Chaudhari, A. Bang, and S. Surana, "Validated stability-indicating high-performance thin-layer chromatographic method for estimation of cefpodoxime proxetil in bulk and in pharmaceutical formulation according to International conference on harmonization guidelines," Journal of Pharmacy and Bioallied Sciences, vol. 4, no. 2, pp. 101-106, 2012.

[20] S. I. Bhoir, P. V. Gaikwad, L. S. Parab, R. N. Shringarpure, S. S. Savant, and P. J. Verma, "RP-HPLC method development and validation for the simultaneous estimation of satranidazole and ofloxacin in pharmaceutical dosage form," Journal of Chromatographic Science, vol. 49, no. 1, pp. 84-87, 2011. 

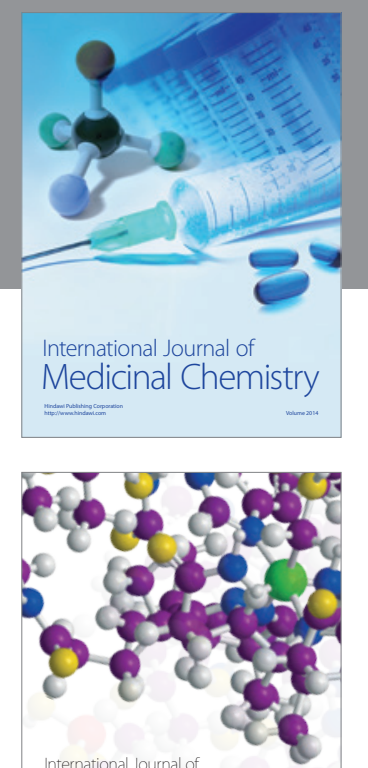

\section{Carbohydrate} Chemistry

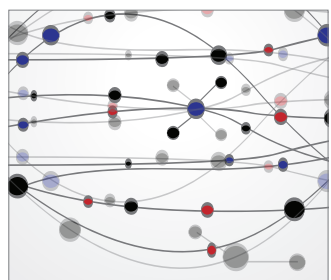

The Scientific World Journal
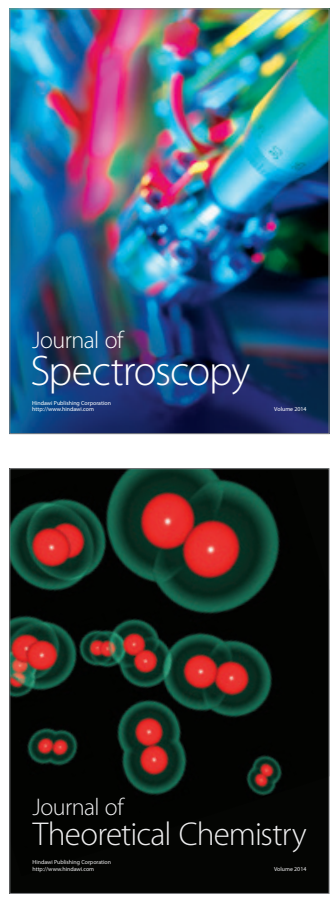
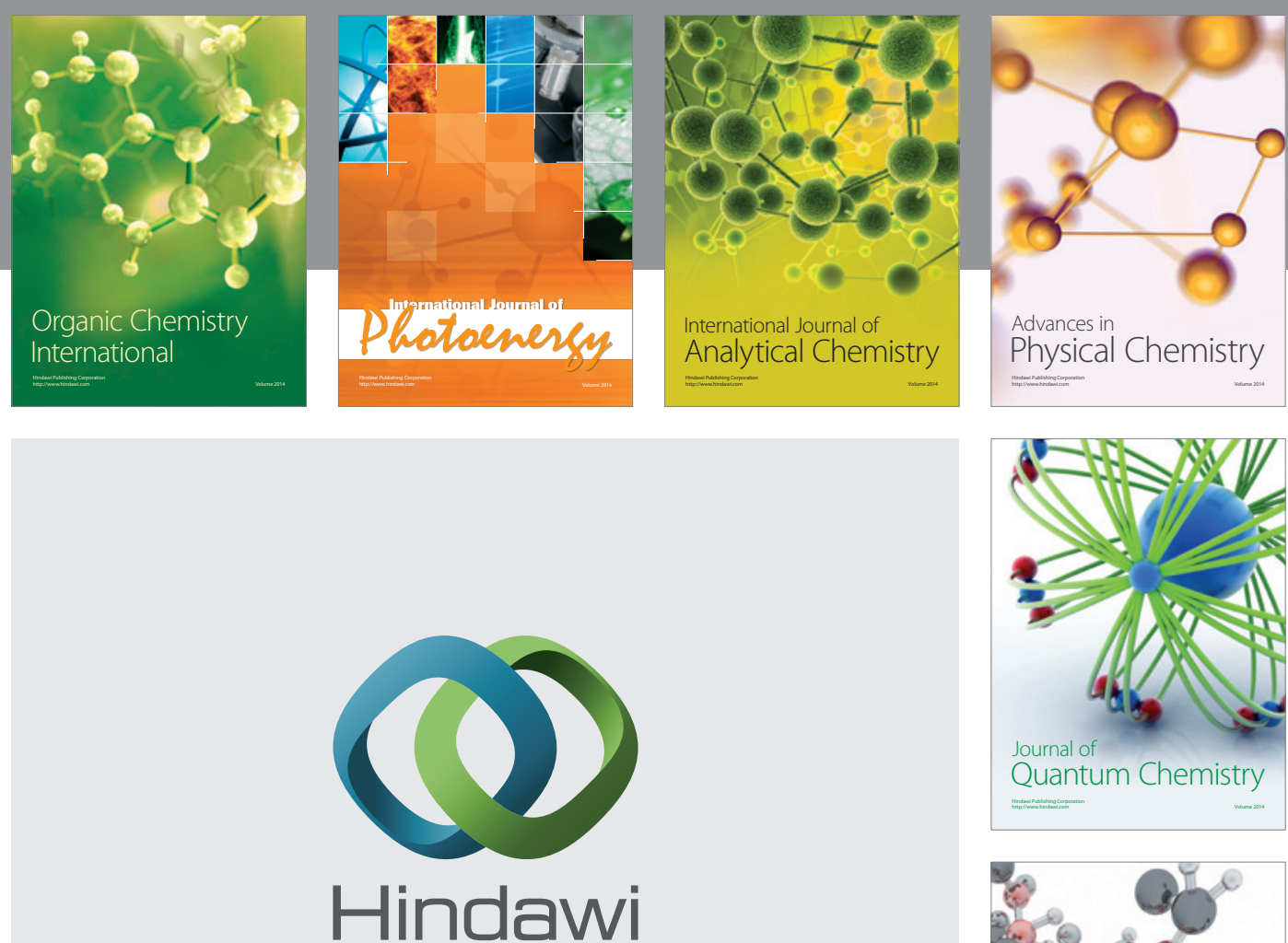

Submit your manuscripts at

http://www.hindawi.com

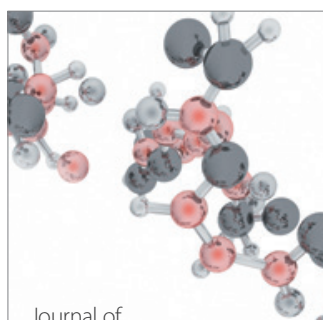

Analytical Methods

in Chemistry

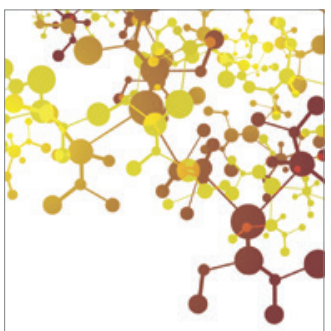

Journal of

Applied Chemistry

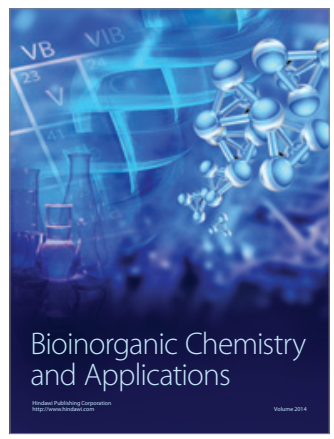

Inorganic Chemistry
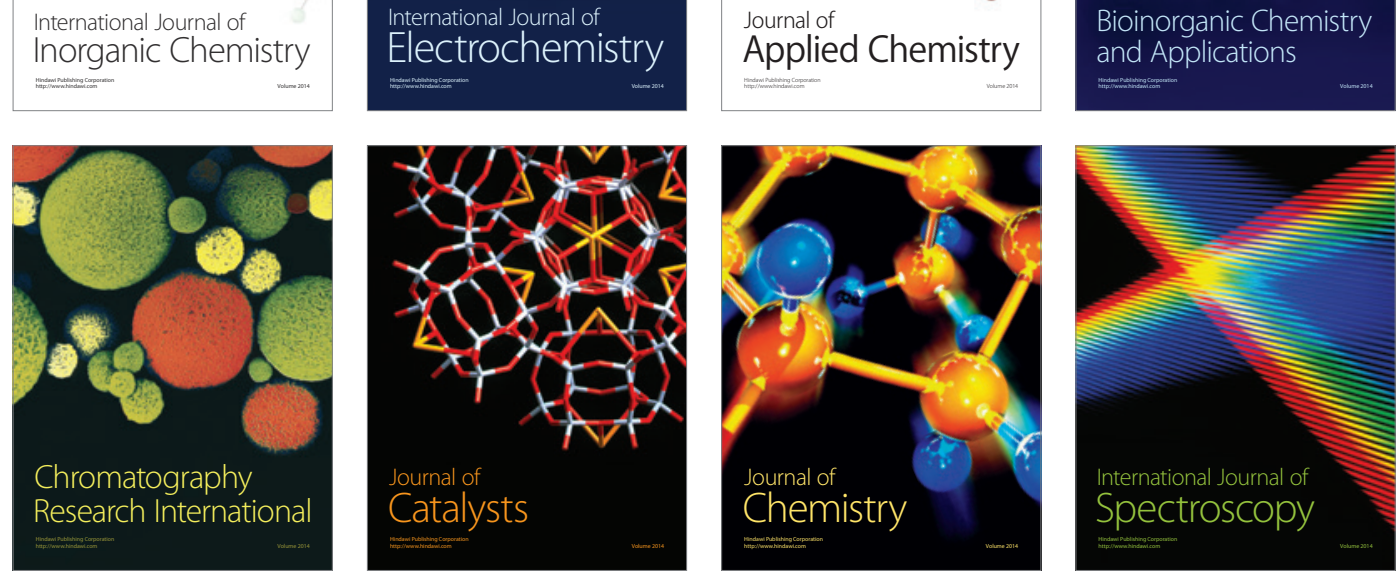